\title{
OPERATIONAL PERFORMANCE OF KINFRA INDUSTRIAL PARKS IN KERALA: SELECT INFERENCES
}

\author{
Dr. P. Noufal \\ Head, \\ Department of Development Economics \\ Dr. B.R. Ambedkar Memorial Government Arts \& Science College \\ Balussery-673612, \\ Kozhikode District, \\ Kerala, India.
}

Article DOI: https://doi.org/10.36713/epra4925

\begin{abstract}
Kerala aims to become one of the top 10 ranking States in the country in terms of ease of doing business and in promotion of a typical business and entrepreneurial culture at par with global standards. Being an active facilitator and industrial catalyst of the State, the Kerala Industrial Infrastructure Development Corporation (KINFRA) has a saga of success in making Kerala as one of the most promising and vibrant business cynosure with leading-edge infrastructure. The industrial parks set up by KINFRA are today recognised as important instruments for promoting rapid industrial development, innovation, competitiveness, productivity and focused growth of the regional economy of the State. It is in the context, the paper attempts to explore the operational performance of KINFRA industrial parks within the ambit of the extent of realisation of its objectives.
\end{abstract}

KEYWORDS: Kerala Industry, Industrial Development, Industrial Parks, Operational Efficiency, KINFRA.

\subsection{INTRODUCTION}

The Industrial and Commercial Policy of the State visualises the setting up and strengthening of theme-based industrial parks in the core competency sectors of the State so as to achieve a 10 per cent industrial growth rate within a couple of years. The vision is to transform Kerala into a vibrant investment destination with an effervescent entrepreneurial society through inclusive and sustainable industrial growth strategies and practices. Industrial parks provide an excellent institutional framework, support services and physical infrastructure and thereby act as policy drivers to foster sufficing investments, employment, competitiveness, sustainable and innovative business strategies and regional economic development. They can provide fertile grounds for leveraging new technologies, learning and innovations, jobs and markets and also prime support for startups and new enterprise incubations. By providing a strong legal and institutional framework, industrial parks pool resources and reduce costs, risks and the delays associated with land acquisition, zoning and permitting. At their best, they align infrastructure provision and agglomeration economies to jolt the industrial growth of the economy. As an innovative industrial initiative, the establishment of industrial parks attempts to explore an ecosystem where productive entrepreneurship germinates, sustains and grows leading to the creation of a more vibrant and dynamic industrial economy in Kerala.

The Kerala Industrial Infrastructure Development Corporation, popularly known as KINFRA acts as the 'industrial catalyst' of the State by promoting the concept of 'industrial parks' in Kerala. It is a statutory body established by the Kerala Industrial Infrastructure Development Act, 1993. As the industrial facilitator of Kerala, KINFRA has completed 25 years of its operation and is having 22 fully operational parks, 7 premier ongoing projects and about 9 major projects on anvil at present. The ambience and flawless infrastructure facilities available in the industrial parks aim to provide a typical business or entrepreneurial culture in the State for the development of a high-tech, nonpolluting and export-oriented industries and thereby create top-notch 'industrial townships' in Kerala. It is in the context, the study attempts to explore the 
operational performance of KINFRA industrial parks within the framework of the extent of realisation of objectives as laid down in the KINFRA Act.

\subsection{LITERATURE REVIEW}

Kiselakova $(2014)^{1}$ states that industrial parks contribute significantly to regional development and revitalise the overall economic situation of the country. It promotes job creation in regional labour market, creates favourable conditions for entrepreneurship and increases the support for innovative businesses to enhance competitiveness and support for export growth. Mani (2014) ${ }^{2}$ observes that Kerala is one of the least industrialised States although it has all the potential of being one. The degree of entrepreneurship from the State is at a very low level and it has continued to be so for a very long time. Given the constraints, he argues that the government has to make concerted efforts to lessen eh negative effects of these constraints if it were to promote industrialisation through the manufacturing route. Saha $(2014)^{3}$ assays how industrial clusters allow firms to stimulate economic growth through increasing their competitiveness and performance of businesses; stimulate innovation through efficient use of research and development; promote new businesses by attracting foreign investments and increasing exports as well as employment opportunities in the domestic economy of Kerala.

Hugar (2013) $)^{4}$ manifests industrial estates as important instruments of local industrial development. The high quality infrastructure and other support services in a well-planned layout provides a tending environment for them and thereby enhances the operational efficiency of the small and medium scale industries operating in the industrial estates. Saleman $(2013)^{5}$ examines how industrial

1 Kiselakova, Dana and Alexander Kiselak (2014). 'Analysis of Macroeconomic Factors for the Establishment of Industrial Parks and their Effects on Regional Development-Empirical Study from Slovakia'. Asian Economic and Financial Review. 4(9): 1220-1236.

2 Mani, Sunil. (2014). 'Industrial Investments in Kerala: Trends, Constraints and Future Prospects'. The Journal of Industrial Statistics. 3(2): 169-198.

3 Saha, Nibedita, Drahomira Pavelkova and Petr Saha (2014). 'Cluster Activities and the Firms Competitiveness: An Empirical Study of the Clusters in India (Kerala)'. Strategic Management Quarterly. 2(2): 109-126.

4 Hugar, S.S. and S.S. Nadkarni (2013). 'A Comparative Study of Cuncolim and Canacona Industrial Estates of Goa'. Indian Streams Research Journal. 3(3): 1-5.

5 Saleman, Yannick and Luke Simon Jordan (2013). The Implementation of Industrial Parks: Some Lessons Learned in India. Washington, DC: World Bank. parks are built and how they fail. At their best, industrial parks align infrastructure provision and agglomeration economies to jolt industrial growth. Schwab (2012) ${ }^{6}$ explores the opportunities to improve the image and competitiveness of industrial parks by capitalising three contemporary concepts, namely: sustainable development with 'green' principles as well as economic stability, the 'creative class' work force and the popularity of mixed use development.

Boja $(2011)^{7}$ states that economic development based on cluster models can bring multiple benefits in terms of regional development and competitiveness in an industry. The major benefits include a more facile access to resources; decreased transportation costs and supply chains; offers a higher degree of specialisation in products and services; technology cooperation or acquisitions; specialised workforce pool and better access to skilled labour; an increased market and opportunities and finally a more cooperative and highly competitive business environment. Srikumar $(2011)^{8}$ sifts that the development of industrial parks by KINFRA with ready-to-use infrastructure facilities provides a strong industrial environment in the State. It covers up the inadequacy of industrial infrastructure in the backward areas and thus finds a solution to the problems of low levels of industrialisation and unemployment in Kerala. Das (2011) ${ }^{9}$ states that cluster development will provide competitive advantage to the firms in terms of productivity, innovation and formation of new businesses which will definitely have its impact on the rural economic and industrial development of India. Innovations like the setting up of general industrial parks, product specific industrial parks, industrial estates and special economic zones (SEZs) have been initiated by the government to give an impetus to the rural industrial base of the economy which provides opportunities for the firms to work and grow in their host place.

Vidova (2010) ${ }^{10}$ opines that industrial parks are one of the most important factors supporting positive

6 Schwab, Suzanne (2012). A New Class for Industrial Parks. Irvine: Department of Planning, Policy and Design, University of California.

7 Boja, Catalin. (2011). 'Cluster Models: Factors and Characteristics'. International Journal of Economic Practices and Theories. 1(1): 34-43.

8 Srikumar, K.N. (2011). 'KINFRA-A Saga of Success'. Kerala Calling. 8(2011): 16-19.

9 Das, R. and A.K. Das. (2011). 'Industrial Cluster: An Approach for Rural Development in North-East India' in International Journal of Trade, Economics and Finance. 2(2): 161-165.

10 Vidova, Jarmila (2010). 'Industrial Parks: History, Their Present and Influence on Employment' in Review of Economic Perspectives. 10(1): 41-58. 
economy development. If an industrial park is linked with a clearly defined goal and intention, it must have a positive influence on revitalising the business environment, transfer of modern technologies, creation of new working places and modernisation of the industry, which all will definitely bring certain synergic effects in the domestic industrial economy. Lai (2005) $)^{11}$ pinpoints that firms located in an industrial cluster enjoy strong local demand, reduced search costs, technology spillovers, specialised labour, infrastructure benefits and informational spillovers which will generate positive externalities from knowledge spillovers, transactional efficiencies and cluster-level scale economies. Cote $(2002)^{12}$ states that industrial parks are large tracts of land, sub-divided and developed for the use of several business entities simultaneously and is distinguished by its shareable infrastructure and close proximity of firms. As self designing systems, they exhibit immense possibility and if they are seeded with sufficient diversity, they can design their own solutions to their problems. At present, industrial parks have begun to address the issue of sustainability as well as ecological integrity and efficiency.

\subsection{RESEARCH PROBLEM}

The low level of industrial development in the backward regions of Kerala is one of the major developmental issues confronting the State today. Development of adequate and commendable infrastructure is an essential pre-requisite for rapid industrialisation and the inadequacy of appropriate infrastructure is a major factor hindering the industrial development of the backward regions of the State. Having been analysed various existing literature, it can be observed that the development of industrial parks has attracted the attention of policymakers as a constructive channel of industrial infrastructure. Industrial parks can develop certain synergies and a typical entrepreneurial culture in the industrial economy of any country. They generally provide an excellent institutional framework, support services and physical infrastructure and are aptly treated as policy drivers to foster sufficing investments, employment, competitiveness, sustainable business strategies and regional economic development. Though the development of industrial

11 Lai, Hsein-Che, Yi-Chia Chiu and Horng-Der Leu (2005). 'Innovation Capacity Comparison of China's Information Technology Industrial Clusters'. Technology Analysis \& Strategic Management. 17(3): 293-315.

12 Cote, Raymond P. and E. Cohen Rosenthal (1998). 'Designing Eco-Industrial Parks: A Synthesis of Some Experiences'. Journal of Cleaner Production. 6: $181-188$ parks is of vital importance in the industrial economy of the country, we do not have much study to explore its economic imperative and efficacy. Thus, it becomes significant to examine the operational efficiency and performance of KINFRA industrial parks with particular reference to the fulfillment of its objectives as laid down in the Kerala Industrial Infrastructure Development Act, 1993.

\subsection{OBJECTIVES OF THE STUDY}

Within the last 25 years of its operation, KINFRA is busy with a mission to make Kerala the most favoured destination for competitive industrial development with the provision of commendable infrastructure and support services. In the context, the study attempts the following objectives:

1. To examine the operational efficiency of KINFRA industrial parks in Kerala.

2. To examine the extent of which KINFRA has fulfilled its objectives.

\subsection{METHODOLOGY}

The methodology of the study is arranged in certain subsections such as: Period of study, Sampling design, Data source(s), Data collection, Tools of analysis, Criteria and scale for measurement and the List of variables for the study.

Period of Study: KINFRA has completed 25 years of its operation in Kerala. The study takes into account only a decennial period of its operation, that is, from February, 2003 to February, 2015 for exploration and analysis.

Sampling Design: There are a total of 22 fully operational industrial parks set up by KINFRA as on $31^{\text {st }}$ March, 2019. There are certain ongoing projects along with some other projects on anvil. The study takes into account only the case of those industrial parks which have been set up before the year 2010 . So the total number of sample is 18 fully operational parks out of a total of 22 .

Data Source(s): The study uses both primary and secondary data. Primary data have been collected from the Head Quarters of KINFRA and also from the sample industrial parks. Secondary data have been collected from various existing sources in print and electronic media.

Data Collection: Two questionnaires were used for collecting data and other information. The first set is used for collecting information from the Head Quarters of KINFRA and the second set is used for collecting information from the sample industrial parks. Both set of questionnaires consists of 6 sections such as: general information, extent of realisation of objectives, growth performance, operational efficiency, major problems and constraints and the future prospects. 
Tools of Analysis: Data have been collected and arranged by using appropriate Likert Scales of different dimensions. Statistical measures such as Mean, Range, Percentages and Weighted Scores were used. Karl Pearson's Coefficient of Correlation is used to measure the degree of association between different parameters. Mood's Median Test, Wilcoxon Signed Rank Test and Friedman's Test of Equality were used to test the major hypotheses.

Criteria \& Scale of Measurement: Likert Scales of different dimensions were used in the study. In order to measure the extent of realisation of objectives, a 7-Point Likert Scale is used and to measure the operational efficiency of industrial parks and to explore the problems and constraints of the parks, 5-Point Likert Scales were used.

List of Variables: The study uses as much as 42 variables arranged under 7 categories for measuring the operational efficiency of industrial parks and about 16 variables for measuring the extent of realisation of objectives of KINFRA.

\subsection{SCOPE AND SIGNIFICANCE OF THE STUDY}

By pioneering the concept of industrial parks', KINFRA provides an ambience for the enterprise and innovation to flourish and thereby profoundly influence the industrial economy of Kerala. KINFRA unleashes the industrial potential of the State and thereby enables its progressive and sustainable industrial development. In the context, it becomes imperative to look into the present status, growth performance, operational efficiency, problems, extent of realisation of objectives and the impact of KINFRA industrial parks on the industrial economy of Kerala, especially within the purview of the new vision, strategy and policies adopted by the Government.

\subsection{OPERATIONAL PERFORMANCE AND EFFECTIVENESS OF KINFRA INDUSTRIAL PARKS IN KERALA}

Operational efficiency encompasses the major strategies and practices meant to improve a company's processes to accomplish the goal of providing consistent and quality services to its stakeholders. It looks at an organisation's capabilities and performance measured against certain prescribed indicators of effectiveness. The study attempts to explore the operational efficiency and performance of KINFRA industrial parks within the ambit of the extent of fulfillment of its objectives as laid down in the Kerala Industrial Infrastructure Development Act, 1993. Select parameters of operational effectiveness such as ease of doing business, support systems and services, client relationship management, standards of business operations, responsive commitments, opportunities for sustainable entrepreneurship and extension services are used. About 42 variables as categorised under 7 major heads are used. Responses were gathered on each of the sub-parameters and the observance status and the weighted score of the major parameter is obtained by using a 5-point likert scale. The operational efficiency in terms of the select parameters is tested and interpreted by using Wilcoxon Signed Rank Test. A snapshot of the list of variables used for assessing the operational effectiveness and performance of KINFRA industrial parks is given in Table-1. 
Table-1

Operational Performance of KINFRA Industrial Parks

(List of Variables)

\begin{tabular}{|c|c|c|}
\hline No. & \multicolumn{2}{|c|}{ List of Variable(s) } \\
\hline 1. & \multicolumn{2}{|c|}{ Ease of Doing Business: } \\
\hline & (i) & Affordability of the lease out period and premium. \\
\hline & (ii) & Flexibility of the terms and conditions. \\
\hline & (iii) & Provision of infrastructure and support services. \\
\hline & (iv) & Provision of common facilities. \\
\hline & (v) & Maintenance of a hassle free business environment. \\
\hline & (vi) & Consistent and continuous communication of key initiatives to the entrepreneurs. \\
\hline \multirow[t]{7}{*}{2.} & \multicolumn{2}{|c|}{ Support Systems and Services: } \\
\hline & (i) & Better and updated information to the entrepreneurs. \\
\hline & (ii) & Framework for the realisation of business objectives. \\
\hline & (iii) & Better administration and initiatives for business elaboration. \\
\hline & (iv) & Promotion of the creative initiatives of the entrepreneurs. \\
\hline & (v) & Controls on the managerial actions of the entrepreneurs. \\
\hline & (vi) & Feasible solutions to the issues and problems of the units. \\
\hline \multirow[t]{7}{*}{3.} & \multicolumn{2}{|c|}{ Client Relationship Management: } \\
\hline & (i) & Existence of a cordial relationship and cooperative environment. \\
\hline & (ii) & Commitment and support of the KINFRA management. \\
\hline & (iii) & Professionalism and courtesy of the KINFRA team. \\
\hline & (iv) & Platform for the innovative ideas and initiatives of the entrepreneurs. \\
\hline & (v) & Freedom of the entrepreneurs to question the decisions and actions of the management. \\
\hline & (vi) & Freedom of the entrepreneurs to revise and modify their business plans. \\
\hline \multirow[t]{7}{*}{4.} & \multicolumn{2}{|c|}{ Standards of Business Operations: } \\
\hline & (i) & Affordable cost and shortest time span. \\
\hline & (ii) & Fullest utilisation of capacity. \\
\hline & (iii) & Optimum use of resources. \\
\hline & (iv) & Management of operating risk. \\
\hline & (v) & Promotional activities. \\
\hline & (vi) & Quality benchmarks. \\
\hline \multirow[t]{7}{*}{5.} & \multicolumn{2}{|c|}{ Responsive Commitments: } \\
\hline & (i) & Locational and localised advantages. \\
\hline & (ii) & Provision of a congenial and innovative environment. \\
\hline & (iii) & Provision of training and development activities. \\
\hline & (iv) & Adherence to the time schedule. \\
\hline & (v) & Leveraging of technology. \\
\hline & (vi) & Efforts to enhance the productivity of employees. \\
\hline \multirow[t]{7}{*}{6.} & \multicolumn{2}{|c|}{ Opportunities for Sustainable Entrepreneurship: } \\
\hline & (i) & Inducement to prospective entrepreneurs. \\
\hline & (ii) & Scope and opportunities for business expansion. \\
\hline & (iii) & Opportunities for the diversification of businesses. \\
\hline & (iv) & Growing relationships with the customers. \\
\hline & (v) & Community involvement and societal commitment. \\
\hline & (vi) & KINFRA as a better choice to start and sustain business. \\
\hline \multirow[t]{7}{*}{7.} & \multicolumn{2}{|c|}{ Extension Services: } \\
\hline & (i) & Strong focus on development. \\
\hline & (ii) & Easy access for optimal performance. \\
\hline & (iii) & Better and effective marketing assistance. \\
\hline & (iv) & Measures for the promotion of exports. \\
\hline & (v) & Better and improved way of doing things. \\
\hline & (vi) & KINFRA as a good place for the prospective entrepreneurs and investors. \\
\hline
\end{tabular}

Each parameter is presumed a composite index as they are having definite subsets of related aspects. The major observations regarding the operational efficiency and performance of KINFRA industrial parks in the industrial landscape of Kerala is listed below:

1. KINFRA is a statutory body set up by the Kerala Industrial Infrastructure Development 
Act, 1993 with the mandate of catering to the industry-specific infrastructure requirements of the State with state-of-the-art facilities in ready- to-use industrial complexes.

2. Being the industrial catalyst of the State, KINFRA aims at the economic development of the industrially backward regions by the setting up of 'theme- based' industrial parks with leading-edge infrastructure and support services so as to promote a typical entrepreneurial culture in Kerala.

3. KINFRA encourages the rapid development of potential industries in the core competency sectors of the economy so as to transform the State into a most favoured investor-friendly business hub with globally accepted standards in quality, technology and management.

4. As the industrial facilitator of Kerala, KINFRA has successfully completed 25 years of its operation and has at its credit 22 fully operational industrial parks, 7 premier ongoing projects and 9 flagship projects on anvil.

5. In terms of the parameter 'ease of doing business', it is observed that the operational efficiency of KINFRA industrial parks is 'mostly effective.' By providing a typical business ambience at par with global standards, KINFRA industrial parks assure quality standards and environment for the start up and sustainable growth of industries in Kerala.

6. In terms of the parameter 'support systems and services', it is observed that the operational efficiency of KINFRA industrial parks is 'mostly effective.' KINFRA industrial parks provide the most specific assistance for the development of industries through the services ranging from information, management, technology, entrepreneurship, policy and extension.

7. In terms of the parameter 'client relationship management', it is observed that the operational efficiency of KINFRA industrial parks is 'mostly effective.' KINFRA attempts to uphold a better client relationship management strategy over the entire period of its operation.
8. In terms of the parameter 'standards of business operations', it is observed that the operational efficiency of KINFRA industrial parks is 'mostly effective.' KINFRA stimulates diverse avenues of business by following certain quality benchmarks and standard ways of doing things and thus drives the direction and pace of innovation that underpins the industrial growth of Kerala.

9. In terms of the parameter 'responsive commitments', it is observed that the operational efficiency of KINFRA industrial parks is 'mostly effective.' KINFRA works in line with the Industrial and Commercial Policy of the Government and thus, continually seeks to improve its services so as to make it as a genuinely purpose-led organisation.

10. In terms of the parameter 'opportunities for sustainable entrepreneurship', it is observed that the operational efficiency of KINFRA industrial parks is 'mostly effective.' KINFRA plays a pivotal role in promoting a typical entrepreneurial culture in Kerala and drives innovations so as to contribute positively to the industrial development of the State.

11. In terms of the parameter 'extension services', it is observed that the operational efficiency of KINFRA industrial parks is 'mostly effective.' KINFRA always attempts to provide the entrepreneurs opportunities for assessing their capabilities for the sustained growth, expansion and diversification of their businesses.

Thus, in terms of the select parameters, the operational efficiency of KINFRA industrial parks is marked as 'mostly effective', signifying KINFRA has proved the premise that a cluster of competing and complementary industries has more to offer on the industrial arena of the State than the very same industries taken in isolation from one another. A snapshot of the operational efficiency of KINFRA industrial parks across the State over the entire period of its operation is given in Table-2. 
Table-2

Operational Efficiency of KINFRA Industrial Parks

(Summary of Responses)

\begin{tabular}{|c|l|c|}
\hline \multicolumn{2}{|l|}{ Parameter(s) of Operational Efficiency } & Performance Status \\
\hline 1 & Ease of doing business. & Mostly Effective \\
\hline 2 & Support systems and services. & Mostly Effective \\
\hline 3 & Client relationship management. & Mostly Effective \\
\hline 4 & Standards of business operations. & Mostly Effective \\
\hline 5 & Responsive commitments. & Mostly Effective \\
\hline 6 & Opportunities for sustainable entrepreneurship & Mostly Effective \\
\hline 7 & Extension services. & Mostly Effective \\
\hline
\end{tabular}

Source: Survey Information.

\subsection{EXTENT OF REALISATION OF OBJECTIVES BY KINFRA}

With the objective of boosting the pace of industrial growth in Kerala, KINFRA has been promoting the concept of industrial parks and has took the lead in the setting up of specialised industrial parks throughout the State. Regarding the extent of realisation of objectives of KINFRA and its industrial parks, as much as 16 parameters based on the explicit objectives as laid down in the KINFRA Act, 1993 were identified. The responses were measured on a 7point likert scale. The most significant observation is that the responses on any of the parameters never fall on the negative range of the scale. None of the parameters fall on the ineffective zones of the scale. To what extent KINFRA has realised its objectives reveal the following inferences:

1. As far as the listed parameters are concerned, it can be observed that the responses on any of the parameters never fall on the ineffective zones of the scale. They spread only on 'completely effective', 'mostly effective' and 'somewhat effective' categories of choice.

2. The objectives upon which the responses reveal the status of 'completely effective' are: (1) effective organisational structure and ambience, (2) attracting entrepreneurs and investments for regional industrial development and (3) promotion of industrial development by developing appropriate 'industrial spots' in the core competency sectors of the economy.
3. The objectives upon which the responses reveal the status of 'mostly effective' are: (1) identification of appropriate industrial sites and developed land for the businesses, (2) establishment of ready-to-use built-up spaces, (3) development of industry-specific infrastructure and support services, (4) allotment of developed land to the entrepreneurs on flexible terms and conditions, (5) coordination with other agencies for the provision of quality infrastructure, (6) generation of sufficient employment opportunities, (7) realisation of the vision and mission of KINFRA and (8) effective control techniques, coordination mechanism and management practices.

4. The objectives upon which the responses reveal the status of 'somewhat effective' are: (1) developing and managing industrial estates, (2) undertaking of different schemes of for the orderly development of different industries, (3) adherence to the time schedule from the procuring of land to its allotment and (4) adherence to the cost estimates for the establishment and maintenance of industrial parks.

Based on the responses obtained on the select parameters of objectives, the Wilcoxon Signed Rank Test (based on Median) is applied and the test results and its interpretation are summarised as follows: 


\begin{tabular}{|l|l|}
\hline $\mathbf{H}_{\mathbf{0}}$ & $\begin{array}{l}\text { The operational performance of KINFRA in realising its } \\
\text { objectives is nugatory. }\end{array}$ \\
\hline Test & Wilcoxon Signed Rank (Median) Test \\
\hline Hypothetical Median & 4 \\
\hline P-value & $1.233^{-5}$ \\
\hline Observed Median & 2 (True location is less than 4) \\
\hline Decision & $\begin{array}{l}\text { Reject the null hypothesis }\left(\mathrm{H}_{0}\right) \text { and accept the alternative } \\
\left.\text { hypothesis ( } \mathrm{H}_{1}\right) \text {. }\end{array}$ \\
\hline $\mathbf{H}_{\mathbf{1}}$ & $\begin{array}{l}\text { The operational performance of KINFRA in realising its } \\
\text { objectives is 'mostly effective' with a standard score of 83 per } \\
\text { cent. }\end{array}$ \\
\hline
\end{tabular}

Having been set the null hypothesis as 'the operational performance of KINFRA in realising its objectives is nugatory', the study uses Wilcoxon Median Test for testing the hypothesis. Assuming a hypothetical median value of 4 in a 7 -point likert scale, the observed median is 2 with a P-value of $1.233^{-5}$. The null hypothesis is therefore rejected and the study accepts the alternative hypothesis, signifying 'the operational performance of KINFRA in realising its objectives is mostly effective.' Being the industrial facilitator of the State, KINFRA always attempts to fulfill its objectives maximum so as to give a fillip to the industrial development of Kerala. KINFRA is equipped to usher better and new avenues of entrepreneurship for the State and has commendable success at its credit throughout the entire period of its operation.

\subsection{CONCLUSION}

Providing exemplary industrial infrastructure to meet the demands of emerging businesses is one of the major challenges facing by the industrial economy of Kerala. KINFRA operates with the mandate of creating a feasible and conducive business environment with state-of-the-art infrastructure so as to boost the process of hasty industrial development in the State. The industrial parks set up by KINFRA are today recognised as important instruments for promoting rapid industrial development, innovation, competitiveness, productivity and focused growth of the regional economy of the State. It has successfully completed 25 years of operation in the provision and development of quality industrial infrastructure with benchmarks of global standards. In terms of the parameters ease of doing business, support systems and services, client relationship management, standards of business operations, responsive commitments, opportunities for sustainable entrepreneurship and extension services, the operational efficiency and performance of KINFRA industrial parks is marked as mostly effective. KINFRA has proved the premise that a cluster of competing and complementary industries has more to offer on the industrial arena of the State than the very same industries taken in isolation from one another.

\section{SELECT REFERENCE}

1. Government of Kerala. (2019). Economic Review 2018. Thiruvananthapuram: Kerala State Planning Board.

2. --- (2019). The Kerala Industrial and Commercial Policy 2018. Thiruvananthapuram: Department of Industries and Commerce.

3. Institute for Studies in Industrial Development (ISID). (2010). SME Clusters in India: Identifying Areas of Intervention for Inclusive Growth. New Delhi: ISID.

4. Noufal, P. (2020). 'The Present Status and Growth Performance of KINFRA Industrial Parks in Kerala' in Strads Research. 7(8): 95109.

5. ---- (2019). Operational Efficiency of KINFRA Industrial Parks and Its Impact on the Industrial Development of Kerala. Unpublished Ph.D. Thesis. University of Calicut. 